\title{
Decreased glutathione levels and impaired antioxidant enzyme activities in drug-naive first-episode schizophrenic patients
}

\author{
Monia Raffa ${ }^{1 *}$, Fatma Atig ${ }^{1}$, Ahmed Mhalla ${ }^{2,3}$, Abdelhamid Kerkeni ${ }^{1}$ and Anwar Mechri ${ }^{2,3}$
}

\begin{abstract}
Background: The aim of this study was to determine glutathione levels and antioxidant enzyme activities in the drug-naive first-episode patients with schizophrenia in comparison with healthy control subjects.

Methods: It was a case-controlled study carried on twenty-three patients (20 men and 3 women, mean age $=29.3$ \pm 7.5 years) recruited in their first-episode of schizophrenia and 40 healthy control subjects ( 36 men and 9 women, mean age $=29.6 \pm 6.2$ years). In patients, the blood samples were obtained prior to the initiation of neuroleptic treatments. Glutathione levels: total glutathione (GSHt), reduced glutathione (GSHr) and oxidized glutathione (GSSG) and antioxidant enzyme activities: superoxide dismutase (SOD), glutathione peroxidase (GPx), catalase (CAT) were determined by spectrophotometry.

Results: GSHt and reduced GSHr were significantly lower in patients than in controls, whereas GSSG was significantly higher in patients. GPx activity was significantly higher in patients compared to control subjects. CAT activity was significantly lower in patients, whereas the SOD activity was comparable to that of controls.

Conclusion: This is a report of decreased plasma levels of GSHt and GSHr, and impaired antioxidant enzyme activities in drug-naive first-episode patients with schizophrenia. The GSH deficit seems to be implicated in psychosis, and may be an important indirect biomarker of oxidative stress in schizophrenia early in the course of illness. Finally, our results provide support for further studies of the possible role of antioxidants as neuroprotective therapeutic strategies for schizophrenia from early stages.
\end{abstract}

\section{Background}

There is strong evidence that oxygen free radicals may play an important role in the pathophysiology of major mental illnesses such as schizophrenia [1,2]. Oxyradicals have a very short life span and usually are inactivated or scavenged by antioxidants before they can inflict damage to lipids, proteins or nucleic acids. The human body has a complex antioxidant defense system (AODS) that includes the antioxidant enzymes: superoxide dismutase (SOD), glutathione peroxidase (GPx) and catalase (CAT). Also more important are the non-enzymatic antioxidants such as glutathione (GSH). Cellular levels of antioxidants respond to levels of oxygen and

\footnotetext{
* Correspondence: raffa_monia@yahoo.com

'Research Laboratory of "Trace elements, free radicals and antioxidants", Biophysical Department, Faculty of Medicine, University of Monastir, Avicene street, Monastir 5000, Tunisia

Full list of author information is available at the end of the article
}

oxyradicals; which enables cells to defend against increased oxyradical production [3]. If produced in excess, or not removed effectively, oxyradicals result in cellular damage. SOD dismutates superoxide $\left(\mathrm{O}_{2}{ }^{--}\right)$to yield hydrogen peroxide $\left(\mathrm{H}_{2} \mathrm{O}_{2}\right)$ and oxygen $\left(\mathrm{O}_{2}\right) . \mathrm{H}_{2} \mathrm{O}_{2}$ is not an oxyradical because it does not have an impaired electron, but it must be promptly removed by CAT [3]. Thus, high SOD activity, which results in increased $\mathrm{H}_{2} \mathrm{O}_{2}$ production, must be accompanied by increased GPx and/or CAT activity to limit injury [4]. GPx provides an effective mechanism against cytosolic injury because it eliminates $\mathrm{H}_{2} \mathrm{O}_{2}$ and lipid peroxides (products of $\mathrm{OH}$ mediated peroxidation products) by reduction utilizing GSH [5]. GPx converts peroxides and hydroxyl radicals into nontoxic forms, often with the concomitant oxidation of reduced glutathione (GSHr) into the oxidized form glutathione disulfide (GSSG) and glutathione reductase recycles GSSG to GSH [4]. GSH 
and other thiol-containing groups also play critical roles as antioxidants. GSH participates in the reduction of oxyradicals and its levels in the brain are high especially during early development [5].

Since oxidative stress is systematic and some of the oxidative products of the brain tissue do end up in the blood, peripheral indices have been accepted to reflect the brain oxidative injury [6]. However, there are conflicting data in the literature on the activities or levels of antioxidant enzymes in patients with schizophrenia. SOD activity in erythrocytes of schizophrenic patients has been reported to be increased [7,8] decreased [9-11] or unchanged [12,13]. GPx activities have been reported to be unchanged [3,9,14-16] but also increased [7,17] or decreased $[11,18,19]$ and CAT activity has been found unchanged [3,13,16] increased [20,21] and decreased $[11,15,22]$. GSH is the brain's dominant antioxidant implicated in the pathophysiology of schizophrenia [23]. There is a $27 \%$ reduction in the cerebrospinal fluid levels of GSH in untreated patients [24] and a similar reduction $(41 \%)$ in the caudate postmortem of schizophrenic patients [25]. Previous studies recorded a significant decrease in the blood levels of total glutathione (GSHt) [26], of GSHr [27] or of GSHt and GSHr [28] in schizophrenic patients in comparison with controls. Furthermore, increased risk of schizophrenia is associated with polymorphisms of genes associated with GSH synthesis [29,30]. To our knowledge, there are few published studies that have evaluated the antioxidant defense system (AODS) in the blood of first-episode schizophrenic patients (FESP) and most of the studies were conducted on populations of the patients with chronic schizophrenia. Thus, it seemed interesting to consider the medication status and the stage of schizophrenia in the evaluation of the AODS changes that manifest in patients.

The purposes of the present study were (1) to assess whether red blood cell (RBC) SOD, GPx, and CAT activities, plasmatic GSHt, GSHr and GSSG levels were altered in the drug-naive FESP as compared to control subjects, (2) if so, to further test whether altered antioxidant defenses were associated with clinical characteristics of patients.

\section{Methods}

\section{Subject selection and diagnosis}

Twenty-three patients ( 20 men and 3 women) with a mean age of $29.3 \pm 7.4$ years (range, 19-45) were recruited in their first-episode of schizophrenia from consecutive admissions at the psychiatric department of the University Hospital of Monastir. They provisionally had DSM-IV-TR criteria for schizophrenia $(n=9)$ and schizophreniform disorder $(\mathrm{n}=14)$ based on the Structured Clinical Interview for DSM-IV-TR [31]. Diagnosis was reconfirmed at 6 months by consensus. Healthy control subjects $(n=45,36$ men and 9 women with a mean age of $29.6 \pm 6.2$ years, range, 22-47) were recruited from blood donors in the blood center of the University Hospital of Monastir. Their current mental status and personal or family history of any mental disorder was assessed by unstructured interviews.

The exclusion criteria considered for the two groups were the same and included the following parameters: seizure disorders, head injury with loss of consciousness, dependence on alcohol and other substances (except dependence on tobacco), vitamin supplementation followed for 6 months prior to inclusion in the study, and denial to take part in the present study. Additional exclusion criteria for the control subjects included personal or family history of psychosis. All subjects signed informed consent after a full explanation of the study. The study was approved by the Local Ethic Committee of the University Hospital of Monastir. The demographic and clinical characteristics of the FESP and the control subjects were summarized in Table 1. Age and gender distribution of the subjects and smoking habit did not differ between patients and controls (Table 1).

\section{Biochemical procedures}

Five milliliters of blood was drawn from control subjects and FESP by simple venipuncture between 7.00 and 9.00 a.m. after overnight fasting and tobacco abstinence for $>$ $12 \mathrm{~h}$. For the patients the blood samples were obtained prior to the initiation of neuroleptic treatments. The samples were centrifuged for $10 \mathrm{~min}$ at $3500 \mathrm{rpm}$. Plasma RBCs were then separated, aliquoted and stored at $-80^{\circ} \mathrm{C}$ until analysis. For all samples, each evaluated parameter was assayed in duplicate. Throughout the investigations the biochemical assays were conducted blind of the available clinical information. The total SOD activities were determined using pyrogallol as substrate by the method of Marklund and Marklund [32]. This method is based on pyrogallol oxidation by the

Table 1 Demographic and clinical features of the patients and the controls

\begin{tabular}{lccc}
\hline $\begin{array}{l}\text { Demographic and clinical } \\
\text { features }\end{array}$ & $\begin{array}{c}\text { Patients } \\
(\mathbf{N}=\mathbf{2 3})\end{array}$ & $\begin{array}{c}\text { Controls } \\
(\mathbf{N}=\mathbf{4 5})\end{array}$ & $\begin{array}{c}\text { p- } \\
\text { values }\end{array}$ \\
\hline Age (mean \pm SD) (years) & $\mathbf{2 9 . 3} \pm \mathbf{7 . 5}$ & $\mathbf{2 9 . 6 \pm}$ & $\mathbf{0 . 9 9 5}$ \\
Min-Max & $\mathbf{1 9 - 4 5}$ & $\mathbf{6 . 2}$ & \\
& & $\mathbf{2 2 - 4 7}$ & \\
Gender (male/female) & $20 / 3$ & $36 / 9$ & 0.477 \\
Smokers (\%) & 56.5 & 46.7 & 0.44 \\
SAPS score (mean \pm SD) & $25.4 \pm 12.2$ & - & \\
SANS score (mean \pm SD) & $\mathbf{2 9 . 5} \pm$ & - & \\
& $\mathbf{1 6 . 5}$ & & \\
\hline
\end{tabular}

Max: maximum, Min: minimum, SAPS: Scale for assessment of positive symptoms, SANS: Scale for assessment of negative symptoms, SD: Standard deviation. 
superoxide anion $\left(\mathrm{O}_{2}{ }^{-}\right)$and its dismutation by SOD. One unit (U) of total SOD is defined as the amount of enzyme required to inhibit the rate of pyrogallol autoxidation by $50 \%$. GPx activity was assayed by the subsequent oxidation of NADPH at $240 \mathrm{~nm}$ with t-buthylhydroperoxide as substrate [33]. While, CAT activity was determined using the method described by Beers and Sizer [34] by measuring hydrogen peroxide decomposition at $240 \mathrm{~nm}$. CAT units (U/mg hemoglobin) were determined as mmol of $\mathrm{H}_{2} \mathrm{O}_{2}$ consumed/s/mg hemoglobin. The total hemoglobin content was measured as cyanmethaemogobine using the drabkin method. The glutathione levels were measured spectrophotometrically in deproteinized blood samples, by the method of Akerboom and Sies [35], using 5,5 dithiobis (2-nitrobenzoic acid). Absorbance values were compared with standard curves generated from known amounts of GSH standards.

\section{Psychopathological assessment}

Patients were rated for psychopathology using the Scale for the Assessment of Positive Symptoms (SAPS) and the Scale for the Assessment of Negative Symptoms (SANS) [36]. The assessments were carried out by trained psychologists.

\section{Statistical analysis}

The Windows computing program Statistical Package for the Social Sciences SPSS 10.0 [37] was used for analyzing the data. The obtained data was presented as mean values \pm standard deviation $(\mathrm{SD})$ and were analyzed using nonparametric statistics. Specifically, between groups, comparisons were examined using Mann-Whitney tests. The adjusted analysis of variance (ANOVA) was used in case the parameters of age, gender, and the smoking habit of the subject were found to have some effects on the levels of glutathione and the activities of the antioxidant enzymes. Finally, the correlations existing between the antioxidant systems and the SAPS and SANS scores in our patients were calculated by using Spearman correlation coefficients. The differences were considered significant at values of $\mathrm{p} \leq 0.05$.

\section{Results}

\section{Antioxidant enzyme activities and glutathione levels}

There was no significant correlation between age and AODS included enzyme activities and glutathione levels, in patients or healthy controls. Similarly, there was no effect of gender on AODS, even though the activities of CAT and GPx were found to be affected by the smoking habit of patients $(\mathrm{U}$ de Mann-Whitney $=24, \mathrm{p}=0.02$ and $U$ de Mann-Whitney $=25, \mathrm{p}=0.04$ respectively). Thus, the differences that appeared in the activities of RBC antioxidant CAT and GPx activities were tested by executing an ANOVA adjusted by the smoking habit of the subjects.

In this study, no significant difference was observed in the RBC SOD activity between FESP and control subjects. RBC GPx activity was significantly higher in patients than in healthy controls with $68.6 \pm 13.5 \mathrm{vs}$. $41.1 \pm 26.3 \mathrm{U} / \mathrm{g} \mathrm{Hb}\left(\mathrm{F}_{1-64}=31.8, \mathrm{p}<0.001\right)$, but $\mathrm{RBC}$ CAT activity was significantly lower in patients than in controls with $212.2 \pm 36.9$ vs. $284.6 \pm 88.2 \mathrm{U} / \mathrm{g} \mathrm{Hb}\left(\mathrm{F}_{1-}\right.$ $\left.{ }_{64}=14.8, \mathrm{p}<0.001\right)($ Table 2$)$. As shown in Table 3 , GSHt and GSHr levels were significantly lower in FESP than in control group with values: $560.4 \pm 123.6 \mu \mathrm{mol} / \mathrm{l}$ vs. $759.5 \pm 260.9 \mu \mathrm{mol} / \mathrm{l}$ (U de Mann-Whitney $=214, \mathrm{p}$ $=0.001)$ for GSHt and $512.1 \pm 117.7 \mu \mathrm{mol} / \mathrm{l} v \mathrm{~s} .732 .2 \pm$ $274.6 \mu \mathrm{mol} / \mathrm{l}$ (U de Mann-Whitney = 185, $\mathrm{p}<0.001$ ) for GSHr, respectively. Whereas, GSSG was significantly higher in patients than in controls ( $U$ de Mann-Whitney $=270, \mathrm{p}=0.013$ ) (Table 3). Additionally, we have not found any significant differences between schizophreniform $(\mathrm{n}=14)$ and schizophrenic patients $(\mathrm{n}=9)$ in terms of antioxidant enzyme activities and glutathione levels.

\section{Correlations between the antioxidant system and the SAPS and SANS scores}

There was a positive correlation between the score of SAPS and the levels of tGSH and rGSH $(r=0.50, p=$ $0.04 ; \mathrm{r}=0.51, \mathrm{p}=0.03$, respectively). However, antioxidant enzyme activities were not significantly correlated to SAPS and SANS scores. Correlation coefficients between SAPS, SOD, GPx and CAT were as follows $(\mathrm{r}=$ $-0.34 ; r=-0.11$ and $r=-0.11$; respectively). Correlation coefficients between SANS and SOD, GPx and CAT were as follows $(r=-0.12 ; r=-0.15$ and $r=-0.12$; respectively) (Table 4$)$.

Table 2 The activities of the RBC antioxidant enzymes in the study groups

\begin{tabular}{lccc}
\hline Antioxidant enzymes & $\begin{array}{c}\text { Patients } \\
(\mathrm{N}=23)\end{array}$ & $\begin{array}{c}\text { Controls } \\
(\mathrm{N}=45)\end{array}$ & p-values \\
\hline SOD (U/mg Hb) & $2.2 \pm 0.6$ & $2.4 \pm 0.6$ & 0.2 \\
Mean \pm SD & $1.5-3.8$ & $1.7-4.6$ & \\
Min-Max & & & \\
GPx (U/gHb) & $68.6 \pm 13.5$ & $41.1 \pm 26.3$ & $<0.001^{*}$ \\
Mean \pm SD & $28.2-122.6$ & $22.9-70.7$ & \\
Min-Max & & & \\
CAT (U/gHb) & $212.2 \pm 36.9$ & $284.6 \pm 88.2$ & $<0.001^{*}$ \\
Mean \pm SD & $157.3-282.5$ & $100.3-499.3$ & \\
Min-Max &
\end{tabular}

CAT: catalase, GPx: glutathione peroxidase, Max: maximum, Min: minimum RBC: red blood cell, SD: standard deviation, SOD: superoxide dismutase. *Adjusted by smoking habit 
Table 3 Glutathione levels in the study group

\begin{tabular}{lccc}
\hline Glutathione levels & $\begin{array}{c}\text { Patients } \\
(\mathrm{N}=23)\end{array}$ & $\begin{array}{c}\text { Controls } \\
(\mathrm{N}=45)\end{array}$ & p-values \\
\hline GSHt $(\mu \mathrm{mol} / \mathrm{l})$ & & & \\
Mean \pm SD & $\mathbf{5 6 0 . 4} \pm 123.6$ & $\mathbf{7 5 9 . 5} \pm 260.9$ & 0.001 \\
Min-max & $402.9-821.2$ & $\mathbf{4 3 0 . 6 - 1 5 3 7}$ & \\
GSHr $(\mu \mathrm{mol} / \mathrm{l})$ & & & \\
Mean \pm SD & $512.1 \pm 117.7$ & $732.2 \pm 274.6$ & $<0.001$ \\
Min-max & $402.9-821.2$ & $374.8-1514.8$ & \\
GSSG ( $\mu \mathrm{mol} / \mathrm{l})$ & & & \\
Mean \pm SD & $47.8 \pm 18.1$ & $35.4 \pm 20.3$ & 0.013 \\
Min-max & $10.6-76.6$ & $6.5-73.2$ & \\
\hline
\end{tabular}

GSHr: reduced glutathione, GSHt: total glutathione, GSSG: oxidized glutathione, Max: maximum, Min: minimum, SD: standard deviation.

\section{Discussion}

The key results of the present study were: (1) the levels of GSHt and GSHr significantly decreased in the drugnaïve FESP in comparison with the control subjects. (2) the group of FESP revealed an increased activity of GPx and a decreased activity of CAT in RBCs. (3) a positive correlation exists between the score of SAPS and the levels of GSHt and GSHr. The findings of this study indicate that some FESP may be poorly equipped to deal with oxidative stress due to impaired antioxidant defenses. Moreover, oxidative stress might play a role in the brain's developmental and maturational processes in the pathogenic cascade of schizophrenia. The findings reported above suggest such a possibility and call for more systematic research on the role of oxidative stress in schizophrenia.

The detailed neurochemical mechanisms underlying the pathophysiology of schizophrenia are not clearly understood. There has been accumulating evidence supporting the involvement of oxidative stress in the pathophysiology of this disease [2]. Prabakaran et al. [38] reported that transcript, protein and metabolite alterations are associated with the mitochondrial function and oxidative stress in the cortex, the liver and the RBCs of schizophrenic patients. The antioxidant system

\begin{tabular}{|c|c|c|}
\hline Antioxidant system & SAPS scores & SANS scores \\
\hline Total glutathione & $0.50 *$ & -0.02 \\
\hline Reduced glutathione & $0.51^{*}$ & -0.05 \\
\hline Oxidized glutathione & 0.16 & 0.17 \\
\hline Glutathione peroxidase & -0.34 & -0.12 \\
\hline Superoxide dismutase & -0.11 & -0.15 \\
\hline Catalase & -0.13 & -0.22 \\
\hline
\end{tabular}

FESP: first-episode schizophrenic patients, SAPS: Scale for assessment of positive symptoms, SANS: Scale for assessment of negative symptoms. ${ }^{*} \mathrm{p}<0.05$ eliminates reactive oxygen species to maintain a reduced environment in cells through enzymatic or non-enzymatic approaches. The most studied antioxidants are the SOD, GPx and CAT enzymes. Notably, CAT and SOD, acting in concert with GPx, constitute the major defense or primary antioxidant enzymes against superoxide radicals [39]. However, it is important to underline the contradictions and the controversial outcomes found in the literature. In fact, these differences can be due to several variables among which are inclusion and exclusion criteria for patient selection, analytical methodologies, testing materials (blood cells vs. plasma or serum), exposure to medication (naïve $v s$. drug withdrawal $v s$. medicated), stages of the disease (acute $v s$. chronic or active $v s$. remission phase), lifestyle or dietary pattern, and the patient's origin. The main reason for the difference between the current study and those previously reported $[3,24,40]$, is likely to be the early stage of illness of our patient sample. Also, our study focused on drug-naïve FESP to show whether the oxidative disturbances which occur during the course of the disease can be related to the degenerative process linked to the symptoms and/or treatment, or rather related to schizophrenia and appear at an early stage of the disease. Studies comparing first-episode and chronic schizophrenic patients would be necessary to further investigate a stage-specific change in AODS in schizophrenia.

In our research, we tried to explore the activities of SOD, GPx and CAT in the RBCs of our collected samples of patients and controls. In the present study, we found that the activity of SOD, a key enzyme in the endogenous antioxidant defense pathways, did not differ between the FESP and controls. Similarly, Mico et al. [41] found no significant difference in SOD activity between early-onset first-psychosis group and the control group. Other studies have reported lower SOD activity in neuroleptic-naïve FESP [3]. High levels of blood SOD were reported in neuroleptic-naive schizophrenic patients [8] and higher activities of SOD in neuroleptic-free schizophrenic patients in comparison with the schizophrenic patients treated with haloperidol [13]. However, in our study, the levels of GPx were significantly higher in the FESP than those in control subjects. The same result observed in the early-onset first-episode psychosis by Mico et al [41]. Yao et al. [13] showed also a significant increase in GPx activity in drug-free schizophrenic patients compared to treated ones. In this case, increased GPx antioxidant activity may reflect a preceding cellular oxidative stress or serve as a compensatory mechanism. Interestingly, the CAT activity was significantly lower in the RBCs of drug-naïve FESP than that in control group. Other studies $[3,41]$ showed no significant difference in CAT activity between early-onset first-psychosis patients and the control subjects. Raffa et 
al. [28] found a significant decrease of CAT activity in neuroleptic-free schizophrenic patients.

On the other hand, it is likely that oxidative stress injury was due to an impaired antioxidant defense in early stage of schizophrenia. Furthermore, because of their impaired antioxidant defense, some patients might be vulnerable to oxidative injury in spite of their normal oxyradical production [42]. In recent decades, biochemical studies have increasingly more often focused on the role of free radicals in the pathogenic of neuropsychiatric diseases such as schizophrenia [43,44]. In addition to the impaired antioxidant enzyme activities, we also found a decreased plasma GSHt and GSHr levels in the drug-naïve FESP. Previous studies recorded a significant decrease in the RBC levels of GSHt [26] or of GSHr [27] in schizophrenic patients in comparison with the controls. Plasmatic GSH level was significantly lower in the FESP [41], magnetic resonance spectroscopy studies have shown that levels of GSH were reduced by $52 \%$ in the prefrontal cortex and by $27 \%$ in the cerebrospinal fluid of drug-naïve schizophrenic patients [24]. However, a spectroscopy study showed that patients with first-episode psychosis had a higher concentration of GSH in the medial temporal lobe than control group [23]. Anomalies in GSH metabolism were also supported by the low expression of the gene of the key GSH-synthesizing enzyme, glutamate cysteine ligase modifier subunit, in patient fibroblasts [30]. The GSH deficit found in this study and in previous reports $[18,25,45,46]$ may be involved in membrane peroxidation and microlesions related to dopamine, which seem to be increased in psychosis, and suggest that GSH may be a possible indirect indicator of damage in neuronal membranes $[47,48]$. This study of the drug-naïve FESP also suggests that the deficit in GSH may underlie the pathophysiology of the disease and is not a consequence of treatment. The converging data in literature, in agreement with our results in FESP, indicate that psychosis is associated with an important brain glutathione deficit. In fact, it could be hypothesized that different etiological mechanisms converge into precipitating a first psychotic episode in individuals with a limited GSH synthesis capacity, after which the psychotic episode develops into a degenerating condition that we call schizophrenia. This could be tested by analyzing glutathione in high-risk populations that are subsequently followed up.

In our patient group, using the SAPS, the presence of positive symptoms was associated with higher levels of GSHt and GSHr. Positive symptoms are associated with subcortical dopamine hyperactivity in schizophrenia [49]. Several studies have revealed that catecholamines, especially dopamine, are associated with free radical generation [47-49]. As suggested in the present study, this may serve as a compensatory or protective mechanism employed to neutralize oxidative stress produced from presumably supra-physiological prefrontal dopamine. Therefore, the hyperdopaminergic state in schizophrenia, induced by still unknown mechanisms, may explain the positive association between positive symptoms and GSH levels in the present study. Although, we should be cautious, our findings support the possibility of using peripheral markers of oxidative and antioxidative system in FESP, taking into account the special sensitivity of the brain to oxidative damage [50].

This study has some limitations. Diagnostic groups were relatively small, and it was difficult to establish in advance a sample size to perform the data analyses because of the paucity of studies with similar design characteristics. A second limitation was the used samples were limited to blood ones. Because the data presents changes in peripheral blood, further work is needed to determine if such changes adequately reflect changes in the brain. Although, recent findings have identified a genetic origin of GSH deficit, which results in the impairment of the GSH synthesis in patients diagnosed with schizophrenia [51]. The decreased levels of GSH and/or the activities of antioxidant enzymes in the peripheral blood of the patients may indicate the occurrence of a systematic reaction that may cause oxidative stress in the brain of schizophrenic patients as is the case in other disorders of the central nervous system [52]. The strengths of the study are the uniformity in age with first-episode and drug-naïve of schizophrenic patients, and the existence of a control group.

\section{Conclusion}

In summary, our study shows that there is impairment in the AODS in drug-naive FESP. GSH deficit seems to be implicated in psychosis, and may be an important indirect biomarker of oxidative stress in first-episode of schizophrenia. Our results provide support for further studies of the possible role of antioxidants as neuroprotective therapeutic strategies for schizophrenia from early stages [6]. Data from the longitudinal study will clarify the possible utility of peripheral markers of oxidative stress as prognostic factors and the effect of neuroleptic drugs on oxidative stress.

\footnotetext{
Abbreviations

(AODS): Antioxidant defense system; (CAT): Catalase; (DSM-IV-TR): Diagnostic and statistical manual of mental disorders; (FESP): First-episodeschizophrenic-patients; (GPx): Glutathione peroxidise; (GSHr): Reduced glutathione; (GSHt): Total glutathione; (GSSG): Oxidized glutathione; (Max): Maximum; (Min): Minimum; (RBC): Red blood cell; (SANS): Scale for assessment of negative symptoms; (SAPS): Scale for assessment of positive symptoms; (SD): Standard deviation; (SOD): Superoxide dismutase.
} 


\section{Acknowledgements}

We want to thank Mr. Moncef Rassas (English department, Faculty of Medicine, Monastir, Tunisia) for his editorial assistance.

\section{Author details}

'Research Laboratory of "Trace elements, free radicals and antioxidants", Biophysical Department, Faculty of Medicine, University of Monastir, Avicene street, Monastir 5000, Tunisia. ${ }^{2}$ Research Laboratory of "Vulnerability to psychotic disorders", Faculty of Medicine, University of Monastir, Avicene street, Monastir 5000, Tunisia. ${ }^{3}$ Department of Psychiatry, University Hospital of Monastir, Avicene street, Monastir 5000, Tunisia.

\section{Authors' contributions}

All the authors made substantial contributions to the design and conception of the study. Particularly, MR wrote the manuscript, contributed to the analysis and interpretation of the data. AM conceived of the study, and participated in its design and coordination and helped to draft the manuscript. AK contributed to the development of the protocol and study instruments. All the authors have been involved in drafting and revising the manuscript, have read, and approved the final manuscript.

\section{Competing interests}

The authors declare that they have no competing interests.

Received: 28 April 2011 Accepted: 2 August 2011

Published: 2 August 2011

\section{References}

1. Zhang M, Zhao Z, He L, Wan C: Ameta-analysis of oxidative stress markers in schizophrenia. Sci China Life Sci 2010, 53:112-124

2. Bitanihirwe Byron KY, Woo Tsun-Ung W: Oxidative stress in schizophrenia: An integrated approach. Neuroscience and Biobehavioral 2011, 35:878-893.

3. Mukherjee S, Mahadik SP, Scheffer R, Correnti EE, Kelkar H: Impaired antioxidant defense at the onset of psychosis. Schizophr Res 1996 19:19-26.

4. Drevet JR: The antioxidant glutathione peroxidase family and spermatozoa: A complex story. MCE. Essent Fatty Acids 2006, 55:45-54.

5. Burton G J, Jauniaux E: Oxidative stress. Best Pract Res Clin Obstet Gynaecol 2010.

6. Mahadik SP, Pillai A, Joshi S, Foster A: Prevention of oxidative stressmediated neuropathology and improved clinical outcome by adjunctive use of a combination of antioxidants and omega- 3 fatty acids in schizophrenia. Int Rev Psychiatry 2006, 18:119-131.

7. Kuloglu M, Ustundag B, Atmaca M, Canatan H, Tezcan AE, Cinkilinc N: Lipid peroxidation and antioxidant enzyme levels in patients with schizophrenia and bipolar disorder. Cell Biochem Funct 2002, 20:171-175.

8. Zhang XY, Zhou DF, Cao LY, Chen DC, Zhu FY, Wu GY: Blood superoxide dismutase level in schizophrenic patients with tardive dyskinesia: association with dyskinetic movements. Schizophr Res 2003, 62:245-250.

9. Akyol O, Herken H, Uz E, Fadillioglu E, Unal S, Sogut S, Ozyurt H, Savaș HA The indices of endogenous oxidative and antioxidative processes in plasma from schizophrenic patients. The possible role of oxidant/ antioxidant imbalance. Prog Neuropsychopharmacol Biol Psychiatry 2002, 26:995-1005

10. Zhang XY, Tan YL, Cao LY, Wu GY, Xu Q, Shen Y, Zhou DF: Antioxidant enzymes and lipid peroxidation in different forms of schizophrenia treated with typical and atypical antipsychotics. Schizophr Res 2006, 81:291-300.

11. Ben Othmen L, Mechri A, Fendri C, Bost M, Chazot G, Gaha L, Kerkeni A: Altered antioxidant defense system in clinically stable patients with schizophrenia and their unaffected siblings. Prog Neuro-psychopharmacol Biol Psychiatry 2008, 32:155-159.

12. Herken H, Uz E, Ozyurt H, Sogut S, Virit O, Akyol O: Evidence that the activities of erythrocyte free radical scavenging enzymes and the products of lipid peroxidation are increased in different forms of schizophrenia. Mol Psychiatry 2001, 6:66-73.

13. Yao JK, Reddy R, Mc Elhinny LG, Van Kammen DP: Effects of haloperidol on antioxidant defense system enzymes in schizophrenia. J Psychiatr Res 1998, 32:385-391.
14. Yao JK, Reddy RD, Van Kammen DP: Human plasma glutathione peroxidase and symptom severity in schizophrenia. Biol Psychiatry 1999, 45:1512-1515.

15. Reddy R, Sahebarao MP, Mukherjee S, Murthy JN: Enzymes of the antioxidant defense system in chronic schizophrenic patients. Biol Psychiatry 1991, 30:409-412

16. Srivastava N, Barthwal MK, Dalal PK, Agarwal AK, Nag D, Srimal RC, Seth PK, Dikshit M: Nitrite content and antioxidant enzyme levels in the blood of schizophrenia patients. Psychopharmacology (Berl) 2001, 158:140-145.

17. Dakhale G, Khanzode S, Khanzode S, Saoji A, Khobragade L, Turankar A: Oxidative damage and schizophrenia: the potential benefit by atypical antipsychotics. Neuropsychobiology 2004, 49:205-209.

18. Ranjekar PK, Hinge A, Hegde MV, Ghate M, Kale A, Sitasawad S, Wagh UV, Debsikdar VB, Mahadik SP: Decreased antioxidant enzymes and membrane essential polyunsaturated fatty acids in schizophrenic and bipolar mood disorder patients. Psychiatry Res 2003, 121:109-122.

19. Carmeli E, Bachar A, Barchad S, Morad M, Merrick J: Antioxidant status in the serum of persons with intellectual disability and hypothyroidism: a pilot study. Res Dev Disabil 2008, 29:431-438.

20. Evans DR, Parikh W, Khan MM, Coussons C, Buckley PF, Mahadik SP: Red blood cell membrane essential fatty acid metabolism in early psychotic patients following antipsychotic drug treatment. Prostaglandins Leukot Essent Fatty Acids 2003, 69:393-399.

21. Pulido R, Jimenez-Escrig A, Orensanz $L$, Saura-Calixto F, Jimenez-Escrig A: Study of plasma antioxidant status in Alzheimer's disease. Eur J Neurol 2005, 12:531-535.

22. Ustundag B, Atmaca M, Kirtas O, Selek S, Metin K, Tezcan E: Total antioxidant response in patients with schizophrenia. Psychiatry Clin Neurosci 2006, 60:458-464.

23. Wood SJ, Berjer GE, Wellard RM, Proffitt TM, Mc Conchie M, Berk M, et al: Medial tempral lobe glutathione concentration in first episode psychosis: A $^{1} \mathrm{H}-\mathrm{MRS}$ investigation. Neurobiol Dis 2009, 3:354-357.

24. Do KQ, Trabesinger AH, Kirsten-Kruger M, Lauer CJ, Dydak U, Hell D, Holsboer F, Boesiger P, Cuénod M: Schizophrenia: glutathione deficit in cerebrospinal fluid and prefrontal cortex in vivo. Eur J Neurosci 2000, 12:3721-3728.

25. Yao JK, Leonard S, Reddy R: Altered glutathione redox state in schizophrenia. Dis Markers 2006, 22:83-93.

26. Pavlovic D, Tamburic V, Stojanovic I, Kocic G, Jevtovic T, Dordevic V: Oxidative stress asmarkers of positive symptoms in schizophrenia. Med Biol 2002, 9:157-161.

27. Altuntas I, Aksoy H, Coskun I, Cayköylü A, Akçay F: Erythrocyte superoxide dismutase and glutathione peroxidase activities, and malondialdehyde and reduced glutathione levels in schizophrenic patients. Clin Chem Lab Med 2000, 38:1277-1281.

28. Raffa M, Mechri A, Othman LB, Fendri C, Gaha L, Kerkeni A: Decreased glutathione levels and antioxidant enzyme activities in untreated and treated schizophrenic patients. Prog Neuropsychopharmacol Biol Psychiatry 2009, 33:1178-1183.

29. Saadat M, Mobayen F, Farrashbandi H: Genetic polymorphisms of glutathione S-transferase T1: a candidate genetic modifier of individual susceptibilty to schizophrenia. Psychiatry Res 2007, 153:87-91.

30. Tosic M, Ott J, Barral S, Bovet P, Deppen P, Gheorghita F, et al: Schizophrenia and oxidative stress: glutamate cysteine ligase modifier as a susceptibility gene. Am J Hum Genet 2006, 79:586-592.

31. American Psychiatric Association: DSM-IV-TR. Diagnostic and Statistical Manual of mental disorders. fourth edition. Washington DC: American Psychiatric Press; 2000

32. Marklund S, Marklund G: Involvement of the superoxide anion radical in the autoxidation of pyrogallol and a convenient assay for superoxide dismutase. Eur J Biochem 1974, 47:469-474.

33. Gunzler WA, Kremers $H$, Flohe L: An improved coupled test procedure for glutathione peroxidase in blood. Z Klin Biochem 1974, 12:444-448.

34. Beer B, Sizer W: A spectrophotometry method for measuring the breakdown of hydrogen peroxide by catalase. J Biol Chem 1952 195:133-139.

35. Akerboom TP, Sies DH: Assay of glutathione, glutathione disulfide and glutathione mixed disulfides in biological samples. In Methods enzymol detoxification and drug metabolism: conjugation and related systems. Edited by: Jakoly W. London: Academic Press; 1981:373-382. 
36. Andreasen NC: Scale for the Assessment of Negative Symptoms University of lowa, lowa City IA; 1983.

37. SPSS.10.0 statistical package for the Social sciences (SPSS) for windows, version 10.0 Chicago.IL: SPSS Inc; 1994.

38. Prabakaran S, Swatton JE, Ryan MM, Huffaker SJ, Huang JT, et al: Mitochondrial dysfunction in schizophrenia: evidence for compromised brain metabolism and oxidative stress. Mol Psychiatry 2004, 7:684-697.

39. Matsuzawa D, Obata T, Shirayama Y, Nonaka H, Kanazawa Y, Yoshitome E, Takanashi J, Matsuda T, Shimizu E, Ikehira H, lyo M, Hashimoto K: Negative correlation between brain glutathione level and negative symptoms in schizophrenia: a 3T 1H-MRS study. PLOS ONE 2008, 4:e1944.

40. Terpstra M, Vaughan TJ, Ugurbil K, Lim KO, Schulz SC, Gruetter R: Validation of glutathione quantitation from STEAM spectra against edited $1 \mathrm{H}$ NMR spectroscopy at 4T: application to schizophrenia. MAGMA 2005, 18:276-282.

41. Mico JA, Rojas-Corrales MO, Gibert-Rahola J, Parellada M, Moreno D, Fraguas $D$, et al: Reduced antioxidant defense in early onset first-episode psychosis: a case control study. BMC Psychiatry 2011, 11:26.

42. Mahadik SP, Mukherjee S, Correnti EE, Scheffer R: Elevated levels of lipid peroxidation production plasma of drug-naive patients at the onset of psychosis. Schizophr Res 1995, 15:66.

43. Mahadik SP, Mukherjee S: Free radical pathology and antioxidant defense in schizophrenia: a review. Schizophr Res 1996, 19:1-17.

44. Ersan S, Bakir S, Erdal Ersan E, Dogan O: Examination of free radical metabolism and antioxidant defense system elements in patients with obsessive-compulsive disorder. Prog neuropsychopharmacol Biol Psychiatry 2006, 6:1039-1042.

45. Ozcan ME, Gulec M, Ozerol E, Polat R, Akyol O: Antioxidant enzyme activities and oxidative stress in affective disorders. Int Clin Psychopharmacol 2004, 19:89-95.

46. Machado-Vieira R, Andreazza AC, Viale Cl, Zanatto V, Cereser V Jr, Da Silva V, et al: Oxidative stress parameters in unmedicated and treated bipolar subjects during initial manic episode: a possible role for lithium antioxidant effects. Neurosci Lett 2007, 421:33-36.

47. Baez S, Segura-Aguilar J, Widersten M, Johansson AS, Mannervik B: Glutathione transferases catalyse the detoxication of oxidized metabolites (o-quinones) of catecholamines and may serve as an antioxidant system preventing degenerative cellular processes. Biochem J 1997, 324:25-28.

48. Stokes AH, Hastings TG, Vrana KE: Cytotoxic and genotoxic potential of dopamine. J Neurosci Res 1999, 55:659-665.

49. Davis KL, Kahn RS, Ko G, Davidson M: Dopamine in schizophrenia: a review and reconceptualization. Am J Psychiatry 1991, 148:1474-1486.

50. Ng F, Berk M, Dean O, Bush Al: Oxidative stress in psychiatric disorders: evidence base and therapeutic implications. Int I Neuropsychopharmacol 2008, 11:851-876.

51. Gysin R, Kraftsik R, Sandell J, Bovet P, Chappuis C, Conus P, et al: Impaired glutathione synthesis in schizophrenia: convergent genetic and functional evidence. Proc Natl Acad Sci USA 2007, 104:16621-16626.

52. Younes-Mhenni S, Frih-Ayed M, Kerkeni A, Bost M, Chazot G: Peripheral blood markers of oxidative stress in Parkinson's disease. Eur Neurol 2007, 58:78-83.

Pre-publication history

The pre-publication history for this paper can be accessed here: http://www.biomedcentral.com/1471-244X/11/124/prepub

doi:10.1186/1471-244X-11-124

Cite this article as: Raffa et al: Decreased glutathione levels and impaired antioxidant enzyme activities in drug-naive first-episode schizophrenic patients. BMC Psychiatry 2011 11:124.

\section{Submit your next manuscript to BioMed Central and take full advantage of:}

- Convenient online submission

- Thorough peer review

- No space constraints or color figure charges

- Immediate publication on acceptance

- Inclusion in PubMed, CAS, Scopus and Google Scholar

- Research which is freely available for redistribution

Submit your manuscript at www.biomedcentral.com/submit
Biomed Central 